\title{
CUSTOS E RENDIMENTOS OPERACIONAIS DA EXTRAÇÃO DE MADEIRA DE EUCALIPTO COM CABO AÉREO
}

\author{
Danilo Simões ${ }^{1}$, Paulo Torres Fenner ${ }^{2}$, Carlos Adolfo Bantel ${ }^{3}$
}

(recebido: 2 de março de 2009; aceito: 31 de março de 2010)

\begin{abstract}
RESUMO: Objetivou-se, neste trabalho, avaliar técnica e economicamente o cabo aéreo na extração de madeira de eucalipto, em regiões montanhosas. A análise técnica englobou um estudo de tempos e movimentos pelo método de tempo contínuo e a produtividade foi determinada por meio do volume em metros cúbicos de madeira extraída. A análise econômica englobou os parâmetros do custo operacional e custo de extração de madeira. Os resultados referem-se ao rendimento operacional efetivo. O custo médio de extração de madeira foi de US\$3.35 por metro cúbico, com rendimento operacional médio, por hora efetiva de trabalho, de $14,16 \mathrm{~m}^{3} \mathrm{~h}^{-1}$.
\end{abstract}

Palavras-chave: Custos de produção, tempos e movimentos, colheita florestal.

\section{COSTS AND OPERATIONAL PERFORMANCE OF EUCALYPTUS WOOD EXTRACTION USING AERIAL CABLE}

\begin{abstract}
This study aimed to technically and economically evaluate the aerial cable in the extraction of eucalyptus wood in mountainous region. The technical analysis comprised a study of time and movements by continuous method and productivity was determined by the volume in cubic meters of wood extracted. Economical analysis comprised operational costs parameters and wood extraction cost. Results referred to effective operational performance. The average cost of extraction of wood was US\$3.35 per cubic meter with operating performance per effective hour of work of $14.16 \mathrm{~m}^{3} \mathrm{~h}^{-1}$.
\end{abstract}

Key words: Production costs, times and movement, timber harvesting.

\section{INTRODUÇÃO}

Diversas empresas florestais ainda utilizam métodos manuais e semimecanizados, apesar de toda a tecnologia à disposição para colheita, em virtude de estarem localizadas em regiões de relevo acidentado e, também, devido à disponibilidade de mão de obra (OLIVEIRA et al., 2006).

De acordo com Leite (1992), áreas acidentadas, condições topográficas desfavoráveis, exigem um nível de planejamento mais apurado, bem como o desenvolvimento de equipamentos específicos para a colheita florestal.

No caso específico de operações de extração de madeira em regiões montanhosas, a oferta de equipamentos é bastante variada. Os sistemas de cabo aéreo, guinchos de tração, balões e helicópteros podem ser aplicados em extração desde áreas levemente onduladas, de declividade suave, até locais com inclinação extrema, alcançando 100\% (STUDIER \& BINKLEY, 1974).
A extração de madeira corresponde à movimentação de toretes por meio de arraste, suspensos por teleféricos ou em tratores autocarregáveis até a margem das estradas (MACHADO et al., 2002).

Segundo Birro et al. (2002), a extração da madeira é um dos pontos críticos da colheita, uma vez que o custo de unidade de madeira de uma etapa chega a ser 25 vezes maior que o transporte principal, em alguns países.

Para a extração de madeira em condições desfavoráveis, que não permite a utilização de sistemas habituais, o uso do cabo aéreo pode ser uma opção adequada tecnicamente e economicamente, em função dos aspectos ambientais e do baixo investimento financeiro despendido.

Diante disso, o conhecimento dos custos e rendimentos operacionais da extração de madeira, por meio de cabo aéreo, em regiões montanhosas e topografias acentuadas, possibilitam a tomada de decisões em projetos futuros mais confiável economicamente, além de permitir

\footnotetext{
${ }^{1}$ Administrador de Empresas, Doutorando em Agronomia - Departamento de Recursos Naturais/Ciências Florestais - Universidade Estadual Paulista - Cx. P. 237 - 18610-307 - Botucatu, SP - simoesdanilo@yahoo.com.br

${ }^{2}$ Engenheiro Florestal, Professor Dr. em Ciências Florestais - Departamento de Recursos Naturais/Ciências Florestais - Universidade Estadual Paulista - Cx. P. 237 - 18610-307 - Botucatu, SP - fenner@fca.unesp.br

${ }^{3}$ Engenheiro Florestal, Doutorando em Agronomia - Departamento de Recursos Naturais/Ciências Florestais - Universidade Estadual Paulista - Cx. P. 237 - 18610-307 - Botucatu, SP - bantel@ig.com.br
} 
um planejamento adequado, que resultará na maximização operacional e minimização dos custos de colheita de madeira.

Objetivou-se, neste estudo, avaliar técnica e economicamente a atividade de extração de madeira de eucalipto, em regiões montanhosas, por meio de cabo aéreo, determinando os rendimentos e custos operacionais.

\section{MATERIAL E MÉTODOS}

\section{1 Área experimental}

A área experimental está localizada nas coordenadas geográficas $22^{\circ} 58^{\prime}$ de Latitude Sul e $45^{\circ} 17^{\prime}$ de Longitude Oeste, no estado de São Paulo, com altitude média de 710 metros acima do nível do mar. O tipo de solo predominante na região é o argilo-arenoso de cor castanho-avermelhado, com topografia caracterizada como montanhosa (EMBRAPA, 1999).

A distância máxima de extração é de 100 metros, com declividade média de $35 \%$, determinada com o uso de um clinômetro ótico manual da marca Breithaup Kassel, modelo 7028 .
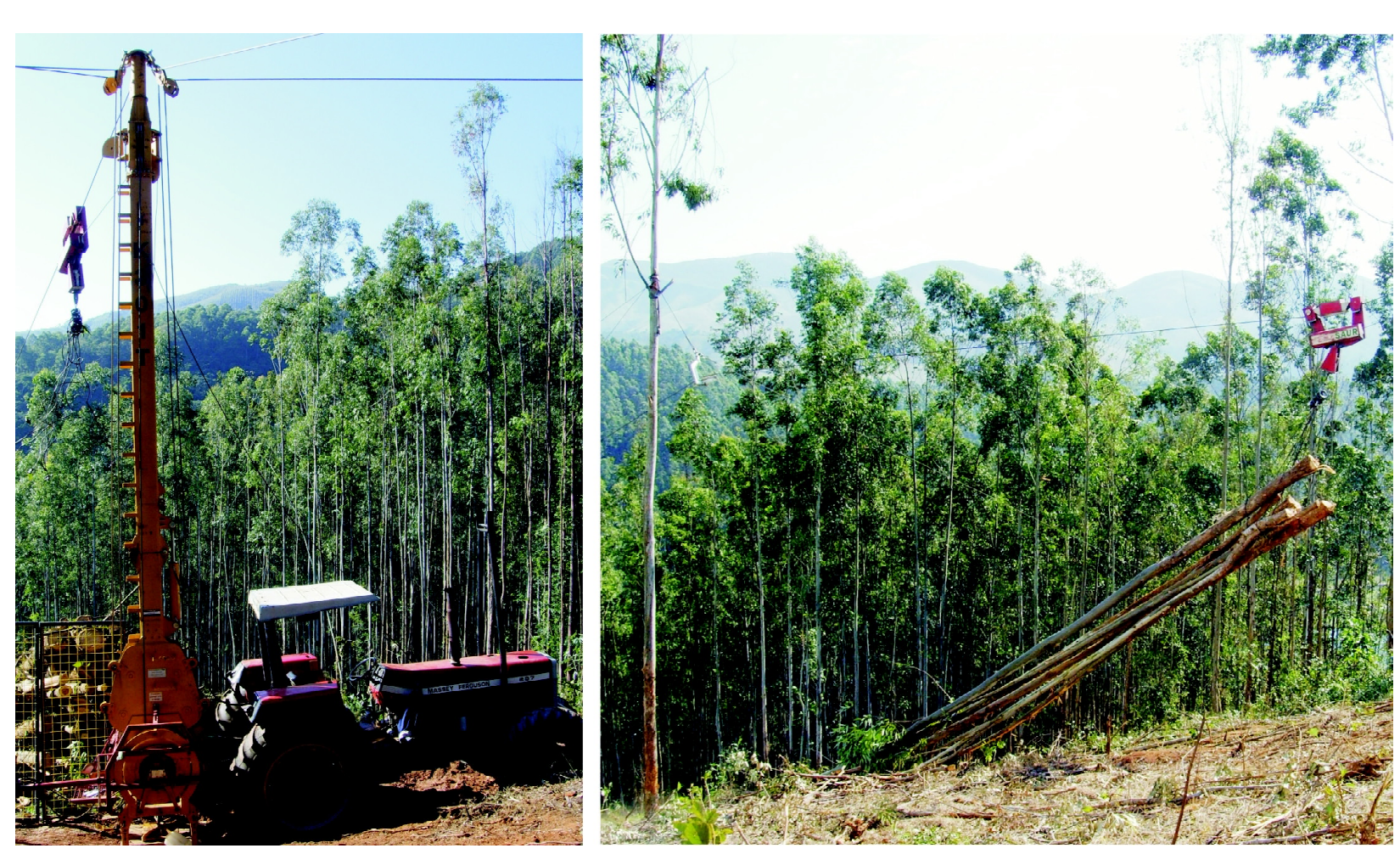

\subsubsection{Caracterização da área}

O estudo foi desenvolvido numa floresta de Eucalyptus grandis de primeiro corte, num talhão com o mesmo sítio silvicultural (site índex), formado por um povoamento homogêneo e equiâneo, seminal, com 84 meses de idade.

No momento da colheita havia em média 1.337 árvores por hectare, com o diâmetro à altura do peito (DAP) médio de 0,15 metros. A altura média do povoamento era de 21,5 metros, com incremento médio anual (IMA) de $42,37 \mathrm{~m}^{3}$ ha ano $^{-1}$ e volume médio com casca de $271 \mathrm{~m}^{3} \mathrm{ha}^{-1}$.

\subsection{Descrição do cabo aéreo}

O cabo aéreo empregado no estudo é da marca Penzsaur, equipado com 4 estropos, executado por uma torre, que foi instalada na parte mais alta do morro, acoplada à parte traseira do trator agrícola ligado à tomada de potência (Figura 1).

Figura 1 - Vista geral do cabo aéreo.

Figure 1 - View of the aerial cable.

Cerne, Lavras, v. 16, n. 2, p. 185-192, abr./jun. 2010 
As principais características técnicas do cabo aéreo avaliado estão detalhadas na Tabela 1 .

Tabela 1 - Características técnicas do cabo aéreo.

Table 1 - Technical characteristics of the aerial cable.

\begin{tabular}{lc}
\hline Modelo & K 301-T \\
Altura da torre $(\mathrm{m})$ & 8,8 \\
Tração média $(\mathrm{kN})$ & 25 \\
Comprimento do cabo de apoio (m) & 400 \\
Espessura do cabo de apoio (mm) & 16 \\
Comprimento do cabo de tração $(\mathrm{m})$ & 500 \\
Espessura do cabo de tração (mm) & 9,5 \\
Cabos de ancoragem & 4 \\
Comprimento dos cabos de ancoragem (m) & 50 \\
Espessura dos cabos de ancoragem (mm) & 15 \\
\hline
\end{tabular}

Fonte: Penzsaur (2009).

\subsection{Descrição do trator agrícola}

O trator agrícola empregado no estudo é da marca Massey Ferguson - modelo MF 297, equipado com motor diesel modelo 1006-6 e potência de rotação nominal de $88,3 \mathrm{~kW}$ e potência máxima na tomada de potência de $81 \mathrm{~kW}$. Apresenta sistema de rodados de pneus com tração $4 \times 4$ e peso com lastro de $6.496 \mathrm{~kg}$.

\subsection{Sistema de colheita}

A colheita foi realizada com uso de motosserra, com eito de derrubada composto por três linhas de árvores e espaçamento de 2,5x2,5 metros. O corte de derrubada das árvores foi realizado de cima para baixo, as quais eram extraídas sem a remoção dos galhos, por um carro de tração, no sentido morro acima.

O cabo aéreo foi alocado numa única linha reta a partir do ponto de instalação da torre de extração. Dessa maneira é possível realizar o arraste lateral das árvores em faixas de $30 \mathrm{~m}$ para ambos os lados, em paralelo ao trajeto do cabo aéreo.

\subsection{Coleta de dados}

A coleta de dados de tempos e movimentos foi efetuada pelo método de cronometragem de tempo contínuo. Esse método caracteriza-se pela medição do tempo sem detenção do cronômetro, isso é, de forma contínua (FENNER, 2002).
Para este estudo cada feixe de árvore extraída, foi considerada como sendo um ciclo operacional, subdivididos nas seguintes atividades parciais efetivas:

- prender estropos: tempo despendido para a fixação dos estropos às árvores;

- soltar estropos: tempo despendido para soltar os estropos enganchados às árvores;

- arrastar árvores: tracionamento das árvores do local de derrubada, até o eito de extração;

- deslocar carregado: tempo do deslocamento do carro de tração com os feixes de árvores, em direção morro acima;

- deslocamento vazio: tempo de retorno do carro de tração, em direção morro abaixo.

Os dados foram coletados nos mesmos horários e condições climáticas, que mantiveram-se sem alterações, com pleno sol durante o período do estudo.

Foi utilizada a amostragem sistemática, sendo o número de ciclos operacionais estimados através da metodologia utilizada por Barnes (1968) por meio da Equação 1. Inicialmente, realizou-se um estudo-piloto dos ciclos operacionais, buscando estabelecer o número mínimo de ciclos, para um erro de amostragem admissível fixado em 5\%, a $95 \%$ de probabilidade.

$n=\frac{t^{2} C V^{2}}{E^{2}}$

onde,

n - número mínimo de ciclos operacionais necessários;

t - valor de t, Student, no nível de probabilidade desejado e (n-1) graus de liberdade;

$\mathrm{CV}$ - coeficiente de variação (\%);

$\mathrm{E}$ - erro admissível (\%).

\subsection{Delineamento experimental}

Para avaliar a influência da distância de extração no desempenho operacional do cabo aéreo, a área experimental foi subdividida em 4 parcelas (Tabela 2).

Tabela 2 - Distâncias de extração de madeira.

Table 2 -Distances of extraction of the wood.

\begin{tabular}{cc}
\hline Parcelas & Distância de extração de madeira $(\mathrm{m})$ \\
\hline 1 & $\geq 0 \mathrm{a} \geq 100$ \\
2 & $\geq 100 \mathrm{a} \geq 200$ \\
3 & $\geq 200 \mathrm{a} \geq 300$ \\
4 & $\geq 300 \mathrm{a} \geq 400$ \\
\hline
\end{tabular}

Cerne, Lavras, v. 16, n. 2, p. 185-192, abr./jun. 2010 
Os resultados obtidos foram submetidos à técnica da análise de variância, para experimentos inteiramente casualizados. Nos casos em que houve diferença estatisticamente significativa foi realizado o teste de Tukey, a $5 \%$ de probabilidade.

\subsection{Rendimento operacional}

Para realizar o cálculo do rendimento operacional da operação de extração com cabo aéreo foi utilizada a (Equação 2):

$$
R=\frac{v}{T}
$$

onde,

$\mathrm{R}$ - rendimento operacional médio $\left(\mathrm{m}^{3} \mathrm{~h}^{-1}\right)$;

$\mathrm{v}$ - volume de madeira, em metros cúbicos de madeira extraída $\left(\mathrm{m}^{3}\right)$;

$\mathrm{T}$ - tempo em horas $(\mathrm{h})$.

$\mathrm{O}$ volume de madeira foi obtido multiplicando-se o número de árvores extraídas pelo volume de cada árvore, determinado por meio de cubagem rigorosa para seções tomadas até a altura comercial através do método preconizado por Smalian (Equação 3):

$V_{i}=\left(\frac{g_{i}+g_{i+1}}{2}\right) \times L$

onde,

$\mathrm{V}_{\mathrm{i}}$ - volume da seção considerada;

$\mathrm{g}_{\mathrm{i}}$ - área seccional da seção mais fina, com casca;

$\mathrm{g}_{\mathrm{i}+1}$ - área secional da seção mais grossa, com casca;

L - comprimento da seção.

\subsection{Determinação dos custos operacionais}

Os custos operacionais da extração de madeira com cabo aéreo foram calculados em dólar por hora de trabalho $\left(\mathrm{US} \$ \mathrm{~h}^{-1}\right)$, utilizando-se a taxa de câmbio de 1 dólar $=$ $\mathrm{R} \$ 1,9213$ de 01/10/2.008.

Para o cálculo do custo fixo, foi considerado um valor de revenda de $47 \%$ do valor inicial do trator agrícola e vida útil de 5 anos. Os valores do trator agrícola, do cabo aéreo e da mão de obra foram fornecidos pela empresa onde desenvolveu-se o estudo. Para o valor inicial do trator agrícola considerou-se também o valor do cabo aéreo. Foi aplicada a metodologia proposta pela American Society of Agricultural Engineers (American Society Agricultural Engineers - ASAE, 2001), conforme equações a seguir.

\subsubsection{Custos fixos $(\mathrm{CF})$}

Os custos fixos são aqueles que não variaram com a quantidade de horas da operação e independeram da produção, sendo compostos pelos juros, custos de depreciação, abrigo, taxas e seguros.

a) Juros

Para o cálculo dos juros considerou-se uma taxa de $10 \%$ a.a. que se refere à utilizada pela empresa (Equação 4):

$J=\frac{V i+V f}{2 \times h} \times r$

onde,

$\mathrm{J}$ - custos com juros (US\$ h $\mathrm{h}^{-1}$ );

$\mathrm{Vi}$ - valor inicial do trator agrícola (US\$);

Vf - valor final do trator agrícola (US\$);

$\mathrm{h}$ - horas efetivas de uso anual;

$\mathrm{r}$ - taxa de juros.

b) Depreciação

O custo de depreciação estimou a perda de valor no decorrer da vida útil do trator florestal (Equação 5):

$D=\frac{V i-V f}{V u \times h}$

onde,

$\mathrm{D}$ - depreciação linear (US\$ $\left.\mathrm{h}^{-1}\right)$;

$\mathrm{Vi}$ - valor inicial do trator agrícola (US\$);

Vf - valor final de revenda ou de sucata do trator agrícola (US\$);

$\mathrm{Vu}$ - vida útil em anos;

$\mathrm{h}$ - horas de uso anual.

c) Abrigo

Foi calculado o custo pago em função do local de abrigo requerido pelo trator agrícola (Equação 6):

$C_{a}=\frac{V i \times F A}{h}$

onde,

$\mathrm{C}_{\mathrm{a}}$ - custo de abrigo do trator agrícola $\left(\mathrm{US} \$ \mathrm{~h}^{-1}\right)$;

$\mathrm{Vi}$ - valor inicial do trator agrícola (US\$);

FA - fator de ajuste $0,75 \%$ do valor inicial do trator agrícola; $\mathrm{h}$ - horas de uso por ano.

Cerne, Lavras, v. 16, n. 2, p. 185-192, abr./jun. 2010 
d) Taxas

Em função dos encargos administrativos, foi considerado um porcentual do valor inicial do trator agrícola, de acordo com o preconizado pela ASAE (2001), conforme a (Equação 7):

$T=\frac{V i \times F A}{h}$

onde,

$\mathrm{T}$ - taxas de administração (US\$ $\mathrm{h}^{-1}$ );

$\mathrm{Vi}$ - valor inicial do trator agrícola (US\$);

FA - fator de ajuste 1,0\% do valor inicial do trator agrícola; $\mathrm{h}$ - horas de uso por ano.

e) Seguros

O custo do seguro foi calculado para a proteção contra os riscos associados com roubo, incêndio e outros (Equação 8):

$S=\frac{V i \times F A}{h}$

onde,

$\mathrm{S}$ - seguros $\left(\mathrm{US} \$ \mathrm{~h}^{-1}\right)$;

$\mathrm{Vi}$ - valor inicial do trator agrícola (US\$);

FA - fator de ajuste $0,25 \%$ do valor inicial do trator agrícola; $\mathrm{h}$ - horas de uso por ano.

\subsubsection{Custos variáveis (CV)}

Os custos variáveis alteraram proporcionalmente em relação ao nível da operação e do tempo despendido para a realização. Os custos variáveis são constituídos por despesas com: combustível, mão de obra, lubrificação, reparos e manutenções.

a) Mão de obra

No custo horário de mão de obra estão inclusos os salários diretos e indiretos e, todos os benefícios que o operador recebe, baseados na quantidade de horas trabalhadas. Devido ao tempo despendido para abastecimento de combustível, lubrificação, manutenção, ausência do trator no campo e transporte foi adotado um fator de ajuste proposto pela ASAE (2001), conforme a (Equação 9):

$$
C m o=\{W \times F A\}
$$

onde,

Cmo - custo do operador por hora (US\$ $\left.\mathrm{h}^{-1}\right)$;

W - salário médio por hora;

FA - fator de ajuste $0,25 \%$.

b) Combustíveis

O custo de combustível foi calculado baseado na quantidade de óleo diesel consumido pelo trator agrícola (Equação 10):

$C c=Q m \times P c$

onde,

Cc - custo de combustível por hora (US\$ $\mathrm{h}^{-1}$ );

Qm - consumo médio de diesel $\left(1 \mathrm{~h}^{-1}\right)$;

Pc - preço do óleo diesel por litro (US\$).

c) Lubrificação

Os custos de lubrificantes foram calculados com fator de ajuste de $15 \%$ dos custos do combustível consumido por hora de trabalho, conforme a metodologia proposta pela ASAE (2001), por meio da (Equação 11):

$C l=F A \times C c$

onde,

$\mathrm{Cl}$ - custo de lubrificação por hora $\left(\mathrm{US} \$ \mathrm{~h}^{-1}\right)$;

FA - fator de ajuste;

$\mathrm{Cc}$ - preço do óleo diesel por litro (US\$ $1^{-1}$ ).

d) Reparos e manutenção

Os custos de reparo e manutenção incidem devido ao uso em condições normais ou em consequência de desgastes dos componentes, acidentes ou deterioração natural do trator agrícola, representados na (Equação 12):

$c_{r m}=\frac{\left(P \times F R_{1}\left(\frac{h+u}{1000}\right)^{F R_{2}}\right)-\left(P \times F R_{1}\left(\frac{h}{1000}\right)^{F R_{2}}\right)}{u}$

onde,

$\mathrm{C}_{\mathrm{rm}}$ - custos de reparo e manutenção (US $\$ \mathrm{~h}^{-1}$ );

$\mathrm{P}$ - valor inicial do trator agrícola (US\$);

$\mathrm{FR}_{1}$ - fator de reparo $1(0,007)$;

$\mathrm{h}$ - horas de uso acumulada, até o início do ano em análise; $\mathrm{FR}_{2}$ - fator de reparo $2(2,0)$;

$\mathrm{u}$ - horas de uso no ano em análise.

Cerne, Lavras, v. 16, n. 2, p. 185-192, abr./jun. 2010 


\subsubsection{Custos operacional total (COT)}

Este custo foi obtido pelo somatório dos custos fixos e variáveis relativos ao trator agrícola avaliado (Equação 13):

$$
C o t=C F+C V
$$

onde,

Cot - custo operacional total do trator agrícola (US\$ $\mathrm{h}^{-1}$ );

$\mathrm{CF}$ - custos fixos (US\$ $\left.\mathrm{h}^{-1}\right)$;

$\mathrm{CV}$ - custos variáveis (US\$ $\mathrm{h}^{-1}$ ).

\subsubsection{Custos de extração de madeira (CEM)}

O custo de extração de madeira (US\$ $\mathrm{m}^{-3}$ ) foi obtido através da divisão dos custos operacionais pelo rendimento operacional efetivo, conforme a (Equação 14):

$$
\operatorname{Cem}=\frac{C o t}{R}
$$

onde,

Cem - custo de extração de madeira (US\$ $\mathrm{m}^{3}$ );

Cot - custo operacional do trator agrícola $\left(\mathrm{US} \$ \mathrm{~h}^{-1}\right)$; $\mathrm{R}$ - rendimento operacional $\left(\mathrm{m}^{3} \mathrm{~h}^{-1}\right)$.

\section{RESULTADOS E DISCUSSÃO}

Foi estabelecido, para um erro de amostragem admissível em 5\%, o número mínimo de 60 ciclos operacionais. Durante o estudo foram observados 68 ciclos, número superior ao fixado como necessário. Foram extraídas 430, árvores com volume médio de $0,3033 \mathrm{~m}^{3}$.

\subsection{Estudo de tempos e movimentos}

Dentre as atividades parciais efetivas que compuseram o ciclo operacional do cabo aéreo verificouse que a atividade parcial, que consumiu maior parte do tempo do ciclo operacional, foi a de prender estropos, com $49,62 \%$ do tempo total. A segunda atividade parcial foi soltar estropos, com $24,25 \%$, seguida das atividades parciais de deslocar carregado com 11,53\%, arrastar árvores com $9,06 \%$ e deslocamento vazio com $5,54 \%$, do tempo total.

A Tabela 3 apresenta a equação estimada que relaciona o número de árvores extraídas e o tempo de extração. Verifica-se que existe forte correlação entre essas duas variáveis, realçada pela equação da linha reta ascendente com $\mathrm{R}^{2}=0,860$, valor este próximo de 1 , indicando um bom ajuste.

Cerne, Lavras, v. 16, n. 2, p. 185-192, abr./jun. 2010
Tabela 3 - Equação estimada para o ciclo operacional do cabo aéreo.

Table 3 - Equations estimated for the operacional cycle of the aerial cable.

\begin{tabular}{cccc}
\hline \multirow{2}{*}{ Cabo aéreo } & Equação estimada & $\mathrm{R}^{2}$ & C.V. (\%) \\
\cline { 2 - 4 } & $\mathrm{Y}=29,393+103,56 . \mathrm{X}$. & 0,860 & 8,07 \\
\hline
\end{tabular}

* $\mathrm{Y}=$ número de árvores; $\mathrm{X}=$ tempo $(\mathrm{h}) ; \mathrm{R}^{2}=$ coeficiente de determinação; C.V.= coeficiente de variação.

\subsection{Rendimento operacional}

Trabalhando em floresta de primeiro corte, com distância máxima de extração de 400 metros, declividade média de $35 \%$ e sem chuva, o rendimento operacional médio efetivo do cabo aéreo foi de $14,16 \mathrm{~m}^{3} \mathrm{~h}^{-1}$.

Conforme a Tabela 4 , pôde-se verificar que os melhores rendimentos operacionais foram obtidos para as parcelas 1 e 2 respectivamente, as quais não diferiram estatisticamente entre si. Esses resultados confirmam Bantel (2006), o qual afirma haver uma tendência na diminuição do rendimento operacional em função da distância de extração.

Tabela 4 - Análise estatística do ciclo operacional do cabo aéreo.

Table 4 - Statistical analysis of the operational cycle of the aerial cable.

\begin{tabular}{cc}
\hline Parcelas & Rendimento operacional médio $\left(\mathrm{m}^{3} \mathrm{~h}^{-1}\right)$ \\
\hline 1 & $23,589 \mathrm{a}$ \\
2 & $19,601 \mathrm{ab}$ \\
3 & $13,604 \mathrm{bc}$ \\
4 & $9,558 \mathrm{~d}$ \\
\hline
\end{tabular}

Médias seguidas de mesma letra não diferem, estatisticamente, entre si, pelo teste de Tukey, a 5\% de probabilidade.

\subsection{Custo operacional}

Diante do somatório dos custos fixos e variáveis, o cabo aéreo apresentou um custo operacional de US\$ 80.90, por hora de trabalho.

A Figura 2 apresenta os porcentuais dos custos operacionais obtidos para o cabo aéreo. O custo fixo correspondeu a $20,76 \%$ e, o custo variável representou $79,24 \%$.

Por causa do trator agrícola empregado no estudo apresentar mais de 21.000 horas de uso, os custos de reparos e manutenção foram os que mais impactaram o montante $(68,56 \%)$. Este porcentual indica que, a partir de 
uma determinada quantidade de horas de uso, os custos com reparos e manutenção serão sempre superiores aos demais itens.

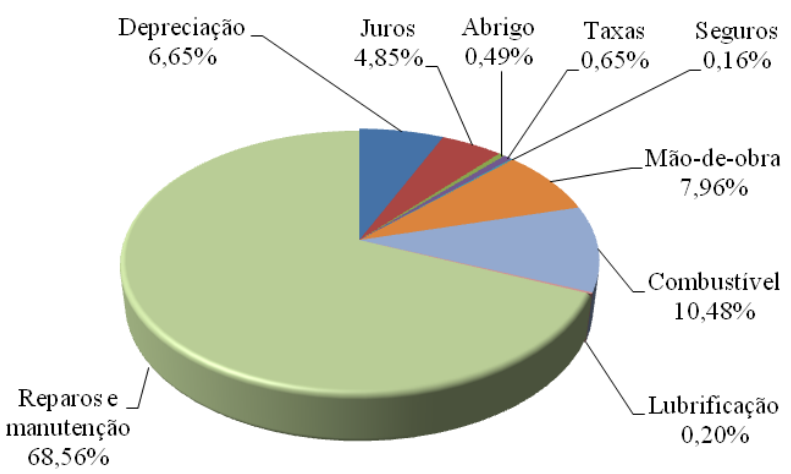

Figura 2 - Porcentuais dos custos fixos e variáveis do cabo aéreo.

Figure 2 - Percentage of the fixed and variable costs of the aerial cable.

\subsection{Custo de extração de madeira}

Considerado o rendimento operacional médio efetivo, o custo médio de extração de madeira resultou em US\$3.35, por metro cúbico.

Souza et al. (2004) afirmam, em seu estudo, que o custo de produção decresce à medida que há um aumento na produtividade. Esse fato pode ser observado na Figura 3 , que apresenta uma curva do tipo exponencial, relacionando o custo de extração de madeira em função do rendimento operacional efetivo do cabo aéreo.

$\mathrm{O}$ custo de extração de madeira comportou-se inversamente ao rendimento operacional, variando de US\$ 40.45 , para o menor rendimento operacional a US\$ 4.05, para o maior rendimento operacional.

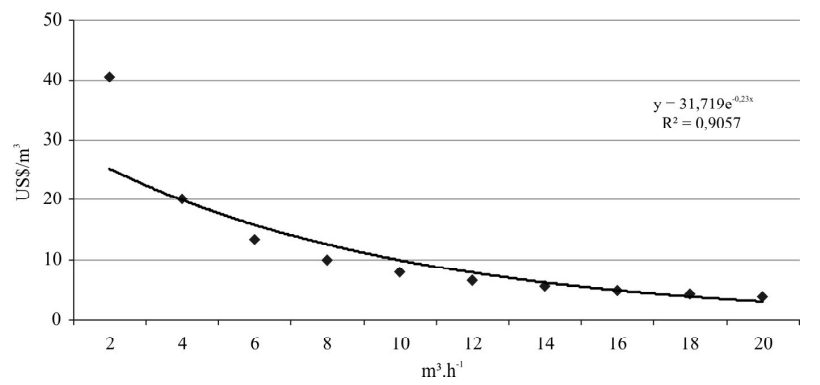

Figura 3 - Comportamento do custo de extração de madeira, em função do rendimento operacional.

Figure 3 - Wood extraction cost behavior as a function of operational performance.

\section{CONCLUSÕES}

As atividades parciais que consumiram a maior parte do tempo do ciclo operacional foram prender e soltar os estropos, com aproximadamente $70 \%$ do tempo total do ciclo;

$\mathrm{O}$ item reparos e manutenção representou o maior porcentual na composição dos custos operacionais;

$\mathrm{O}$ rendimento operacional do cabo aéreo variou de 9,55 a 23,58 $\mathrm{m}^{3} \mathrm{~h}^{-1}$, com custo médio de extração de US\$ 3.35. O custo operacional foi de US $\$ 80.90$, por hora efetiva de trabalho;

A distância de extração de madeira influenciou amplamente o rendimento operacional do cabo aéreo.

\section{REFERÊNCIAS BIBLIOGRÁFICAS}

AMERICAN SOCIETY OF AGRICULTURAL ENGINEERS. ASAE standards 2001: machinery, equipment, and buildings: operating costs. Ames, 2001. 226 p. (ASAE D472-3).

BANTEL, C. A. Análise de extração de madeira de eucalipto com forwarder em floresta de primeira e segunda rotação. 2006. 126 f. Dissertação (Mestrado em Energia na Agricultura) Faculdade de Ciências Agronômicas, Universidade Estadual Paulista, Botucatu, 2006.

BARNES, R. M. Motion and time study: design and measurement of work. 6. ed. New York: J. Willey, 1968. 799 p.

BIRRO, M. H. B.; MACHADO, C. C.; SOUZA, A. P.; MINETTI, L. J. Avaliação técnica e econômica da extração de madeira de eucalipto com "track-skidder" em região montanhosa. Revista Árvore, Viçosa, v. 26, n. 5, p. 525-532, 2002.

EMPRESA BRASILEIRA DE PESQUISA AGROPECUÁRIA. Centro Nacional de Pesquisa de Solo. Sistema brasileiro de classificação de solos. Rio de Janeiro: Embrapa-CNPS, 1999. 412 p.

FENNER, P. T. Métodos de cronometragem e a obtenção de rendimentos para as atividades de colheita de madeira. Botucatu: UNESP, 2002. 14 p.

LEITE, A. M. P. Análise de fatores que afetam o desempenho de veículos e o custo de transporte de madeira no distrito florestal do Vale do Rio Doce - MG. 1992. Dissertação (Mestrado em Ciência Florestal) - Universidade Federal de Viçosa, Viçosa, 1992.

MACHADO, C. C.; SANTOS, S. L. M.; SOUZA, A. P.; FERNANDES, H. C. Análise de custo de subsistemas de colheita de toras de eucalipto de diferentes comprimentos e volumes por árvore. Revista Árvore, Viçosa, v. 26, n. 1, p. 73-81, 2002.

Cerne, Lavras, v. 16, n. 2, p. 185-192, abr./jun. 2010 
OLIVEIRA, R. J.; MACHADO, C. C.; SOUZA, A. P.; LEITE, H. G. Avaliação técnica e econômica da extração de madeira de eucalipto com "clambunk skidder". Revista Árvore, Viçosa, v. 30, n. 2, p. 267-275, 2006.

PENZSAUR. Equipamentos florestais. Disponível em: <http:/ i/www.penzsaur.com.br/principal.php?id menu=produtos \&id=29>. Acesso em: 2 fev. 2009.
SOUZA, A. P.; MINETTE, L. J.; MOREIRA, F. M. T.; MACHADO, C. C.; SILVA, K. R. Análise do desempenho da máquina 'slingshot' em subsistemas de colheita em florestas de eucalipto. Revista Brasileira de Engenharia Agrícola e Ambiental, Campina Grande, v. 8, n. 2/3, p. 316-320, 2004.

STUDIER, D.; BINKLEY, V. W. Cable Logging Systems DTM/Pacific Northeast Station. Oregon: Forest Service/ USDA, 1974. $210 \mathrm{p}$. 